\title{
La troisième révolution touristique - Diversification des pratiques et des stratégies
}

\section{Cécile Clergeau}

\section{(2) OpenEdition}

Journals

Édition électronique

URL : http://journals.openedition.org/tourisme/1236

DOI : 10.4000/tourisme.1236

ISSN : 2492-7503

Éditeur

Éditions touristiques européennes

Référence électronique

Cécile Clergeau, « La troisième révolution touristique - Diversification des pratiques et des stratégies », Mondes du Tourisme [En ligne], Hors-série | 2016, mis en ligne le 01 septembre 2016, consulté le 23 septembre 2020. URL : http://journals.openedition.org/tourisme/1236 ; DOI : https://doi.org/10.4000/ tourisme.1236

Ce document a été généré automatiquement le 23 septembre 2020

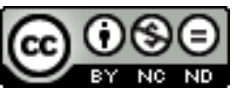

Mondes du tourisme est mis à disposition selon les termes de la licence Creative Commons Attribution - Pas d'Utilisation Commerciale - Pas de Modification 4.0 International. 


\title{
La troisième révolution touristique - Diversification des pratiques et des stratégies
}

\author{
Cécile Clergeau
}

1 La troisième révolution touristique, qui semble se dérouler sous nos yeux, s'inscrit dans un contexte économique, géopolitique, social et technologique, lui même caractérisé par des mutations profondes et extrêmement rapides. Le déplacement du centre de gravité de l'économie mondiale vers l'est, l'hyperconcurrence globale, les vagues d'innovation technologiques mais aussi les transformations sociétales et l'émergence de nouvelles demandes sociales contribuent à façonner un environnement instable, complexe et incertain auquel le tourisme s'adapte tout en participant à sa dynamique d'évolution. S'il se voit bouleversé par Internet, il devient l'un des pionniers du ecommerce. Si la consommation de masse fait place à une demande d'individualisation et consommation raisonnée, il facilite, en spécialiste de la coproduction, l'autonomisation des touristes et s'engage dans la consommation collaborative. Son développement rend rentables les A380 ou autres super-paquebots, que la découverte de nouveaux matériaux a rendu techniquement possibles. Le tourisme vit et se développe ainsi en interaction constante avec son environnement. La troisième révolution dans laquelle il est engagé fait écho aux mutations majeures que connaît ce nouveau millénaire.

2 De même, les mutations du système touristique sont le fruit d'une dynamique d'évolution interactive entre les pratiques des touristes et les stratégies des acteurs du tourisme - territoires et entreprises. Comprendre les ressorts d'une troisième révolution touristique ne peut se faire sans une analyse compréhensive de ces interactions. Les recherches présentées ici partagent ce constat et offrent un regard fécond sur les processus à l'œuvre: processus de diffusion mais aussi d'évolution des pratiques ou des imaginaires touristiques, processus de redéfinition des modèles d'affaires et d'innovation, ou processus de réorganisations territoriales. 
3 Les imaginaires touristiques sont au cœur de la recherche de Lise Piquerey, qui en analyse leur diffusion à travers l'histoire de la carte postale. L'auteur nous montre que derrière cet objet, qui véhicule nos imaginaires de touristes, se dessine une véritable stratégie des acteurs touristiques. Si autrefois le caractère élitiste des stations de sport d'hiver était prioritairement évoqué, on assiste aujourd'hui, montre l'auteur, à une uniformisation des images autour d'une montagnité standardisée.

4 Au-delà des imaginaires, Véronique Mondou et Benjamin Taunay s'intéressent aux pratiques et en particulier à cette pratique, nouvelle pour les touristes chinois, qu'est la croisière. Encouragés par le gouvernement chinois qui s'engage dans des travaux d'infrastructure notables, les grands croisiéristes internationaux investissent l'empire du milieu et y voient l'opportunité d'offrir une seconde vie à des unités probablement déclassées aux yeux des touristes américains. Si les touristes chinois sont séduits par ces vacances à l'américaine, ils les vivent à la chinoise, c'est-à-dire développent leurs propres pratiques. Et l'on peut parier que les croisiéristes adapteront, comme le font les grandes chaines hôtelières, leur offre aux spécificités des besoins des touristes.

5 Cette dynamique interactive est aussi questionnée par Jérôme Piriou lorsqu'il analyse la dimension régionale du système touristique en s'appuyant sur les réseaux de mobilités touristiques. Cette approche, très originale, fait du touriste - et de ses pratiques spatiales - un acteur majeur des lieux touristiques. L'auteur offre alors une perspective de reconstruction des lieux touristiques non plus sur la base d'une organisation administrative ni même sur celle d'une action volontaire des acteurs du tourisme mais bien sur celle des pratiques de mobilité, de la façon dont les touristes s'approprient les espaces.

6 L'impérieuse nécessité de décloisonnement des territoires peut aussi émaner des acteurs locaux et être à l'origine d'innovations structurantes, comme le montrent les recherches d'olivier Bessy sur le North Face Ultra Trail du Mont-Blanc. Un territoire touristique soumis à une concurrence forte, qui voit les pratiques de loisirs montagnards évoluer, situé à cheval sur trois pays, s'engage sous l'impulsion des acteurs locaux dans l'organisation d'un événement construit par et pour le territoire. Rappelant que les ressources touristiques sont des construits qui résultent du jeu des acteurs constitués en territoire, l'auteur nous offre ici un éclairage riche sur la dynamique d'innovation dans une perspective très empreinte d'évolutionnisme.

7 Si l'évolution caractérise les ressources touristiques, elle est aussi le fait des pratiques professionnelles, comme en témoignent les recherches de Clémence Perrin-Malterre. En réponse à l'émergence d'une demande pour un tourisme durable et de nouvelles modalités de consommation touristiques, les prestataires sportifs de moyenne montagne qu'elle a rencontrés proposent de nouvelles offres expérientielles ancrées dans les valeurs du développement durable. La lecture proposée en termes de logique d'action permet d'éclairer cette dynamique interactive entre les demandes des touristes et le projet des prestataires, leur histoire, leur territoire, leurs valeurs. C'est la genèse d'une intention stratégique que nous révèle ici l'auteur.

8 La compréhension de cette intention stratégique des acteurs du tourisme exige parfois une réflexion conceptuelle préalable lorsque le cadre analytique reste insuffisamment développé. C'est l'exercice auquel se livrent Cécile Clergeau et Erfan Marghobi. Alors que les effets conjugués de la révolution Internet et d'une forte demande d'autonomisation ont bouleversé la filière tourisme, ils proposent une réflexion sur les modèles d'affaires des opérateurs touristiques, et plus spécifiquement sur les 
propositions de valeur des intermédiaires du tourisme. Enrichissant la littérature relative à l'intermédiation avec les spécificités coproductives et réticulaires de l'activité touristique, ils mettent en évidence six fonctions majeures remplies par ces acteurs qui peuvent être source de valeur pour les touristes.

\section{AUTEUR}

\section{CÉCILE CLERGEAU}

Professeur en sciences de gestion, LEMNA, IEMN-IAE, université de Nantes, cecile.clergeau@univnantes.fr 